\title{
Protein expression of elF4E and integrin av $\beta 6$ in colon cancer can predict clinical significance, reveal their correlation and imply possible mechanism of interaction
}

Zhengchuan Niu ${ }^{1,2+}$, Jiayong Wang ${ }^{1+}$, Shahbaz Muhammad ${ }^{1,2}$, Weibo Niu', Enyu Liu', Cheng Peng ${ }^{1}$, Benjia Liang ${ }^{1,2}$, Qi Sun ${ }^{1,2}$, Shinichi Obo ${ }^{1}$, Zhaobin He1, Song Liu1', Xueqing Zou ${ }^{1,2}$ and Jun Niu ${ }^{1 *}$

\begin{abstract}
Background: Both eukaryotic translation initiation factor 4E (elF4E) and integrin av $\beta 6$ play an important role in the development and progression of cancer. The aim of this study was to investigate the expression of elF4E and Integrin av $\beta 6$, their clinical significance as well as the two proteins' correlation in colonic carcinoma tissues.

Results: The expression levels of elF4E and integrin av $\beta 6$ were analyzed in colon cancerous and paraneoplastic tissues of 138 cases via tissue microarray (TMA)- immunohistochemistry. And their clinical significance as well as the two proteins' correlation was also investigated. The expression of elF4E was significantly associated with clinical TNM stage $(P=0.009)$, while $T$ stage $(P=0.011)$ and TNM stage $(P=0.012)$ were significantly associated with integrin avß6 expression. Moderately weak correlation exists between the two proteins $(r=0.299, P<0.001)$. The survival analysis by Kaplan-Meier and Cox regression model showed that protein expression of high elF4E and positive integrin av $\beta 6$, as independent prognostic factors $(R R=2.417, P=0.001$ and $R R=2.393, P=0.001)$, tended to have a significantly poorer 5 -year survival rate $(P=0.013$ and 0.025 , respectively, the log-rank test).

Conclusion: elF4E and Integrin av $\beta 6$ were indicators of tumor's progression and poor prognosis of patients with colon cancer. And the potential signaling loop involving them may provide a helpful therapeutic target in prevention and treatment of colon cancer.
\end{abstract}

Keywords: elF4E, Integrin avß6, Colon cancer, TMA, ERK, mTOR

\section{Introduction}

Colon cancer is one of the leading causes of cancer-related deaths worldwide. With the improvement of current living standards and environmental degradation, its morbidity has been on the rise year by year [1]. Both eIF4E and integrin $\alpha v \beta 6$ can play important roles in the development and progression of colonic carcinoma [2-4].

Eukaryotic initiation factor 4E (eIF4E), a 25-kDa cap binding protein, delivers cellular mRNAs to the eIF4F translation initiation complex by binding the $5^{\prime}$-cap structure of these mRNAs [5]. Only about $10 \%$ of mRNAs

\footnotetext{
*Correspondence: junniu120@163.com

${ }^{\dagger}$ Equal contributors

'Department of Hepatobiliary Surgery, Qilu Hospital, Shandong University,

Jinan, Shandong 250012, PR China

Full list of author information is available at the end of the article
}

with 5'UTRs of sufficient length (>200 nt) and threedimensional steric hindrance require the assistance of the eIF4E for efficient translation [6]. eIF4E overexpression can selectively affect transport of specific transcripts and up-regulate the translation of a limited pool of mRNAs with long G-C rich 5'-UTRs and complex structure, encoding proteins involved in cellular growth, angiogenesis, survival, tumorigenesis, and metastasis,such as cyclin D1, c-myc, vascular endothelial growth factor (VEGF), fibroblast growth factor (FGF-2), matrix metalloprotease 9 (MMP-9) [2,7-9]. It is considered as a central regulator of malignancy. eIF4E overexpression has been demonstrated in carcinomas of breast, colon, prostate, bladder, cervix, lung, head and neck (reviewed in [9]). 
Integrins are a family of heterodimeric cell-adhesion molecules composed of two non-covalently bound transmembrane subunits $(18 \alpha$-subunits and $8 \beta$-subunits reported) [10]. These proteins collectively mediate cellular adhesion to extracellular matrix (ECM) and modulate cell proliferation, migration, invasion, and survival by activating intracellular signaling pathways [11]. The $\beta 6$ integrin subunit with $\alpha \mathrm{v}$, its sole binding partner, is an epithelialcell-restricted antigen, which is reported to be expressed in epithelial cancers (lung, breast, pancreas, ovary, oropharynx and colon), as well as during tissue remodeling events (e.g., fibrosis, wound healing) $[12,13]$. Integrin $\alpha v \beta 6$ plays an pivotal role in various aspects of cancer progression [14].

Integrin-mediated signals have been known to contribute to malignancy by regulating transcription [15]. On the other side, recent studies indicated they could also selectively enhance translation initiation of protein synthesis relating to malignancy, through activation of eIF4E via signal pathway of PI-3 K/Akt/mTOR and Ras/ERK/MNK [16-18]. However, the correlation between eIF4E and integrin $\alpha v \beta 6$ and their possible interaction at molecular level are still not clearly known. The aim of our present study was to explore the coexpression and clinical significance of eIF4E combined with integrin $\alpha v \beta 6$ in colon cancer, which could provide a theoretical basis for further study of molecular mechanism in therapeutic intervention.

\section{Results}

The expression of integrin $\beta 6$ and elF4E in normal and neoplastic colon tissue

For eIF4E cohort, 10 tumor cases could not be stained as negative expression, and positive rate was $92.8 \%$, with 74 high expression (Figure 1, Table 1). For integrin $\alpha v \beta 6$, 54 cases were positive expression, and 84 were negative (Figure 2, Table 1). And the normal para-neoplastic tissues for the two markers were all negative staining.

\section{Clinicopathologic data}

After our TMA-IHC staining, all 138 cases for eIF4E and integrin $\alpha v \beta 6$ were assessable. The detailed clinicopathologic data for eIF4E and integrin $\alpha v \beta 6$ are outlined in Table 1.

\section{Association between elF4E and clinicopathologic variables and patient survival}

There was significant association between eIF4E and TNM stage $(P=0.009)$. The high eIF4E rate of TNM III-IV specimens was $65.2 \%$, much more than that of TNM I - II 43.1\%. According to the standard of $\mathrm{P}<0.05$, eIF4E expression has no significant association with other clinicopathologic factors, tumor's anatomical location included, while P-Values of T stage, $\mathrm{N}$ stage and $\mathrm{M}$ stage on eIF4E were all between 0.05 and 0.10 .
Survival curves were generated through the KaplanMeier survival analysis, Patients with high eIF4E expression had a significantly poorer overall survival than those with low expression ( $\mathrm{P}=0.013$, The log-rank test, $\left.X^{2}=6.418\right)$. Patient survival over time on eIF4E expression is illustrated in Figure 3.

\section{Association between integrin av $\beta 6$ and clinicopathologic variables and patient survival}

There was significant association between integrin $\alpha v \beta 6$ expression and $\mathrm{T}$ stage $(\mathrm{P}=0.011)$, TNM stage $(\mathrm{P}=0.012)$. The positive integrin $\alpha \mathrm{v} \beta 6$ rate of TNM III-IV specimens was $50.0 \%$, much more than that of TNM I - II $29.2 \%$. Based on the standard of $\mathrm{P}<0.05$,integrin $\alpha \mathrm{v} \beta 6$ expression has no association with other clinicopathologic factors including age, gender, tumor's anatomical location, pathology grade, $\mathrm{N}$ stage and $\mathrm{M}$ stage.

Patients with high positive $\alpha v \beta 6$ expression had a significantly poorer overall survival rate than those with negative expression ( $\mathrm{P}=0.025$, The log-rank test, $\left.\chi^{2}=5.012\right)$. Patient survival over time on eIF4E expression is illustrated in Figure 4.

\section{The correlation between integrin av $\beta 6$ and elF4E expression in colon cancer}

Positive integrin $\alpha v \beta 6$ expression was observed in $52.7 \%$ of high eIF4E expression tissue, while the rate in low eIF4E expression tissue was $23.4 \%$. Based on the Spearman correlation analysis, integrin $\alpha \mathrm{v} \beta 6$ expression had a positive correlation with eIF4E expression $(r=0.299, \mathrm{P}<0.001$, Table 2).

These 138 cases were stratified according to eIF4E and integrin $\alpha v \beta 6$ expression into 4 groups: group 1 , low eIF4E/(-) integrin $\alpha v \beta 6(n=49)$; group 2, low eIF4E/(+) integrin $\alpha v \beta 6$ ( $n=15)$; group 3 , high eIF4E/(-) integrin $\alpha v \beta 6$ ( $n=35$ ); and group 4, high eIF4E/(+) integrin $\alpha v \beta 6$ $(\mathrm{n}=39)$. Patients with high eIF4E/ $(+)$ integrin $\alpha v \beta 6$ had a significantly poorer overall survival rate than other groups $\left(\mathrm{P}=0.028\right.$, The log-rank test, $\left.\chi^{2}=9.091\right)$. Patient survival over time on eIF4E with integrin $\alpha v \beta 6$ expression is illustrated in Figure 5.

\section{Univariate and multivariate analysis for prognosis of patients with colon cancer}

Univariate and multivariate data analyses were performed using the Cox proportional hazards regression model to determine the prognostic value of eIF4E and integrin $\alpha v \beta 6$ expression. Older age at diagnosis, high eIF4E expression and positive expression of $\alpha v \beta 6$ were the factors to predict a poor prognosis in univariate analysis $(\mathrm{P}<0.001,0.016$, 0.028 ,respectively) (Shown in Table 3 ). Then the variables with $\mathrm{P}<0.10$ were chosen to conduct multivariate analysis, we revealed that high eIF4E expression and positive expression of $\alpha v \beta 6$ were unfavorable independent prognostic 

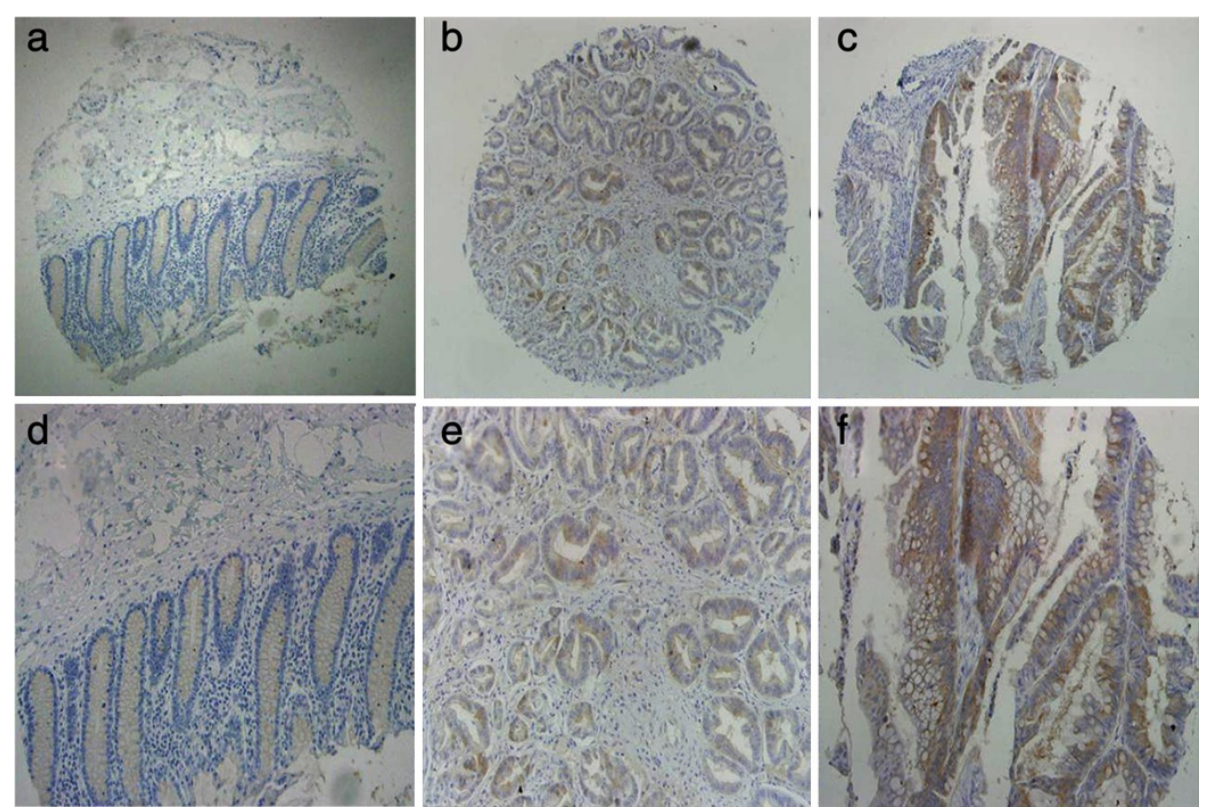

Figure 1 elF4E expression in human colonic cancer. First row: (a), (b), (c) (Scale bar 200 m.); second row: (d), (e), (f), corresponding to each figure above (Scale bar $100 \mu \mathrm{m}$ ). (a) and (d) was obtained from paracancerous normal tissue of patient with colon cancer, with negative staining. (b) and (e) was obtained from colonic carcinoma tissue, with low elF4E expression. (c) and (f) was obtained from colonic carcinoma, with high elF4E expression.

factors (relative risk (RR): 2.417 and 2.393; $\mathrm{P}=0.001$ and 0.001 ,respectively), while increased age, poor/undifferentiated pathology grade were also independent prognostic factors (RR: 1.114 and 2.195; $\mathrm{P}<0.001$ and 0.003 , respectively) (Shown in Table 3).

\section{Discussion}

Colorectal cancer has a higher morbidity and mortality in developed countries [19]. Despite improvements made in screening and treatments during the past years, the clinical outcome of colon cancer remains unsatisfactory. Understanding the molecular mechanism of tumorigenesis would contribute to treatment of patients with this disease.

Over the past decades, the contribution of the mRNA cap-binding protein, eIF-4E, to malignant transformation and progression has been illuminated. eIF4E gene is reported to be recognized as an proto-oncogene in vivo,and the extent of eIF4E overexpression can predict cancer recurrence and outcome in head neck squamous cell carcinoma (HNSCC), breast cancer and lung cancer $[9,20]$. In our present study, patients with high expression eIF4E tended to have a poorer prognosis than those with low expression. And the level of eIF4E expression had significant association with TNM stage, while P-Values of $\mathrm{T}$ stage, $\mathrm{N}$ stage and $\mathrm{M}$ stage respectively on eIF4E were all between 0.05 and 0.10 . From this point, we could speculate that, to some extent, the expression of eIF4E was related to tumor's metastasis and progression. In brief, the association between eIF4E expression and poor prognosis could be explained by the hypothesis of "strong and weak mRNAs". Translation of strong mRNAs (e.g. those encoding housekeeping proteins such as betaactin) will quickly reach a maximum in the presence of low levels of free eIF4E while weak mRNAs are poorly translated. With the increasing number of free activated eIF4E, the translation of these "weak mRNAs" relating to malignancy is disproportionately enhanced, which contributes to the malignant activities $[21,22]$.

The integrin $\alpha v \beta 6$ occurs in many epithelial tumors and has been considered to play a prominent role in tumor invasion and metastasis [14]. Recently, it was reported as an independent unfavorable prognostic indicator in aggressive colonic and gastric carcinomas of humans $[12,13]$, which was confirmed in our study according to the Cox regression model. Similar to the study of Bates [12], our results also showed that the $\alpha \mathrm{v} \beta 6$ expression were significantly associated with clinical stage and the depth of invasion of tumors. These results could be explained logically by our previous studies, that $\alpha v \beta 6$ serves to direct growth factor-activated ERK to downstream cytoplasmic targets involved in regulating cell growth, apoptosis and cytoskeletal reorganization [23,24], and in promoting cellular migration by mediating MMP-9 secretion [25].

Integrin-dependent translational control in cancer progression has been widely investigated and recognized in recent years [16]. The mechanism involves the ability of 
Table 1 Association between elF4E expression, integrin av $\beta 6$ expression and clinicopathologic variables in colon cancer cases

\begin{tabular}{|c|c|c|c|c|c|c|c|}
\hline \multirow[t]{2}{*}{ Clinicopathological factors } & \multirow[t]{2}{*}{$\mathbf{n}$} & \multicolumn{2}{|c|}{ elF4E expression } & \multirow[t]{2}{*}{ Value } & \multicolumn{2}{|c|}{ Integrin av $\beta 6$ expression } & \multirow[t]{2}{*}{ P Value } \\
\hline & & High $(n=74)$ & Low $(n=64)$ & & Positive $(n=54)$ & Negative $(n=84)$ & \\
\hline Gender & & & & 0.345 & & & 0.927 \\
\hline Male & 76 & 38 & 38 & & 30 & 46 & \\
\hline Female & 62 & 36 & 26 & & 24 & 38 & \\
\hline Age(years) & & & & 0.874 & & & 0.108 \\
\hline$<60$ & 70 & 38 & 32 & & 32 & 38 & \\
\hline$\geq 60$ & 68 & 36 & 32 & & 22 & 46 & \\
\hline Tumor anatomical location & & & & 0.634 & & & 0.773 \\
\hline Right hemicolon cancer & 72 & 32 & 40 & & 43 & 29 & \\
\hline Left hemicolon cancer & 66 & 32 & 34 & & 41 & 25 & \\
\hline T stage & & & & 0.072 & & & 0.011 \\
\hline $\mathrm{T} 1^{\#}$ & 1 & 0 & 1 & & 0 & 1 & \\
\hline $\mathrm{T}^{\#}$ & 13 & 8 & 5 & & 2 & 11 & \\
\hline T3 & 55 & 23 & 32 & & 17 & 38 & \\
\hline $\mathrm{T} 4$ & 69 & 43 & 26 & & 35 & 34 & \\
\hline N stage & & & & 0.067 & & & 0.109 \\
\hline NO & 76 & 34 & 42 & & 26 & 50 & \\
\hline N1 & 44 & 28 & 16 & & 17 & 27 & \\
\hline $\mathrm{N} 2$ & 18 & 12 & 6 & & 11 & 7 & \\
\hline \multicolumn{8}{|l|}{ M stage } \\
\hline MO & 114 & 57 & 57 & 0.063 & 40 & 74 & 0.034 \\
\hline M1 & 24 & 17 & 7 & & 14 & 10 & \\
\hline TNM stage & & & & 0.009 & & & 0.012 \\
\hline I- II & 72 & 31 & 41 & & 21 & 51 & \\
\hline III-IV & 66 & 43 & 23 & & 33 & 33 & \\
\hline Differentiation & & & & 0.959 & & & 0.209 \\
\hline Well & 50 & 26 & 24 & & 15 & 35 & \\
\hline Moderate & 55 & 30 & 25 & & 23 & 32 & \\
\hline Poor/undifferentiated & 33 & 18 & 15 & & 16 & 17 & \\
\hline Survival (60-month follow-up) & & & & $0.013^{*}$ & & & $0.025^{*}$ \\
\hline Death & 63 & 40 & 23 & & 30 & 33 & \\
\hline Censored & 75 & 34 & 41 & & 24 & 51 & \\
\hline
\end{tabular}

Footnote: "Date of T1 and T2 were combined into one set for chi-square test.

*Log-rank test.

integrins to activate the PI-3 K/Akt/mTOR and RasERK-MNK pathway, which subsequently enhance eIF4E function through the inhibition of 4E-BP1 [16-18,26] and phosphorylation of eIF4E at ser209 by MNK [27]. Released eIF4E, accompanied with eIF4G and eIF4A, is then able to engage and activate eIF4F complex, leading to translation initiation of genes associated with malignancy. The role of integrin on translation has been addressed in models requiring integrin $\beta 3$, integrin $\beta 4$, and Integrin $\beta 1$ (reviewed in [16]).
In this study, we revealed that high expression of eIF4E combined with positive $\alpha v \beta 6$ can predict a poorer prognosis. And their expressions were positively correlated in colon cancer. However, integrin $\alpha v \beta 6$ dependent translational control hasn't been investigated before. As a member of integrin families, integrin $\alpha v \beta 6$ could trigger ERK pathway, leading to the activation of downstream signals $[23,24]$. According to the theoretical basis mentioned above, we can logically speculate that integrin $\alpha v \beta 6$ probably could also mediate the activation of eIF4E, leading to translation 

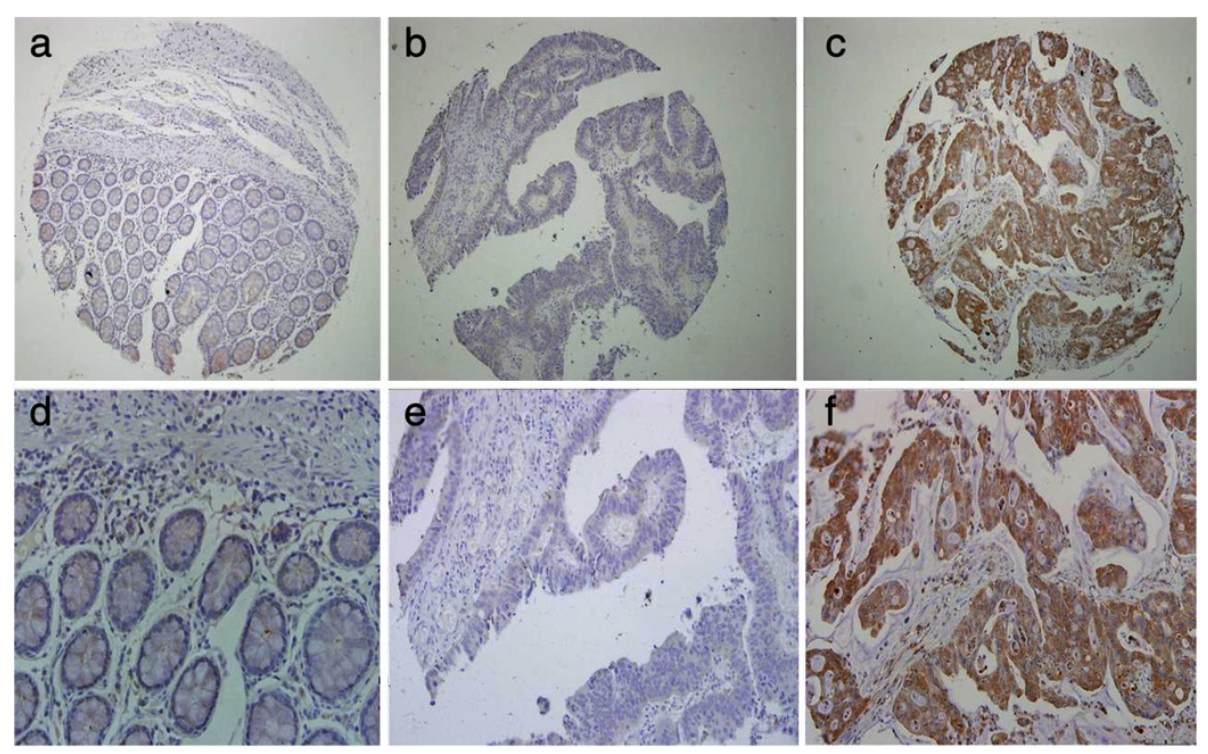

Figure 2 Integrin $\beta 6$ expression in human colonic cancer. First row: (a), (b), (c) (Scale bar $200 \mu \mathrm{m}$.); second row: (d), (e), (f), corresponding to each figure above (Scale bar $100 \mu \mathrm{m}$ ). (a) and (d) was obtained from paracancerous normal tissue of patient with colon cancer, with negative staining. (b) and (e) was obtained from colonic carcinoma tissue,with negative Integrin $\beta 6$ expression. (c) and (f) was obtained from colonic carcinoma, with positive Integrin $\beta 6$ expression.

of "weak mRNA" consequently. On the other side, another bold but reasonable hypothesis is that the activated eIF4E could up-regulate the protein synthesis of Integrin $\beta 6$, as the mRNA of Integrin $\beta 6$ has long 5 ' -UTRs with rich GC, complex structure (Gene ID: 3694, from NCBI), meeting the criteria of "weak mRNAs". Thus, a signal loop involving eIF4E andav $\beta 6$ probably exists to play a key role in tumor cellular growth and migration. Of course, our further work

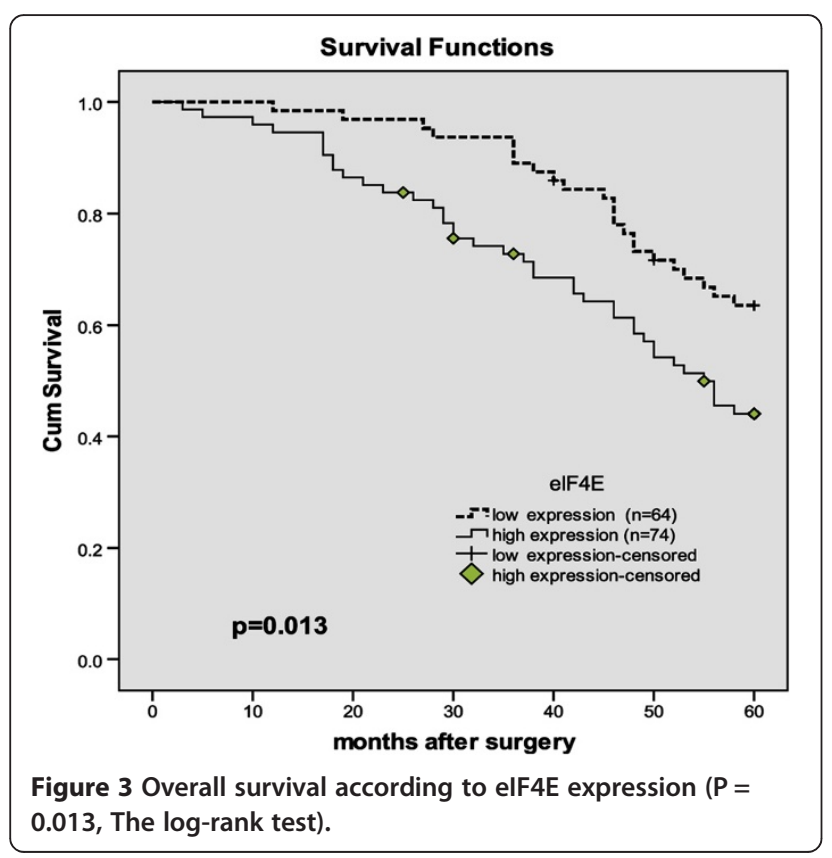

is to demonstrate our hypotheses and determine whether it can be translated into real clinical benefit.

\section{Conclusion}

In summary, our findings indicated that the levels of eIF4E and $\alpha v \beta 6$ expression are elevated in colonic carcinoma, which were associated with tumor progression and poor prognosis of patients with colon cancer. Additionally,

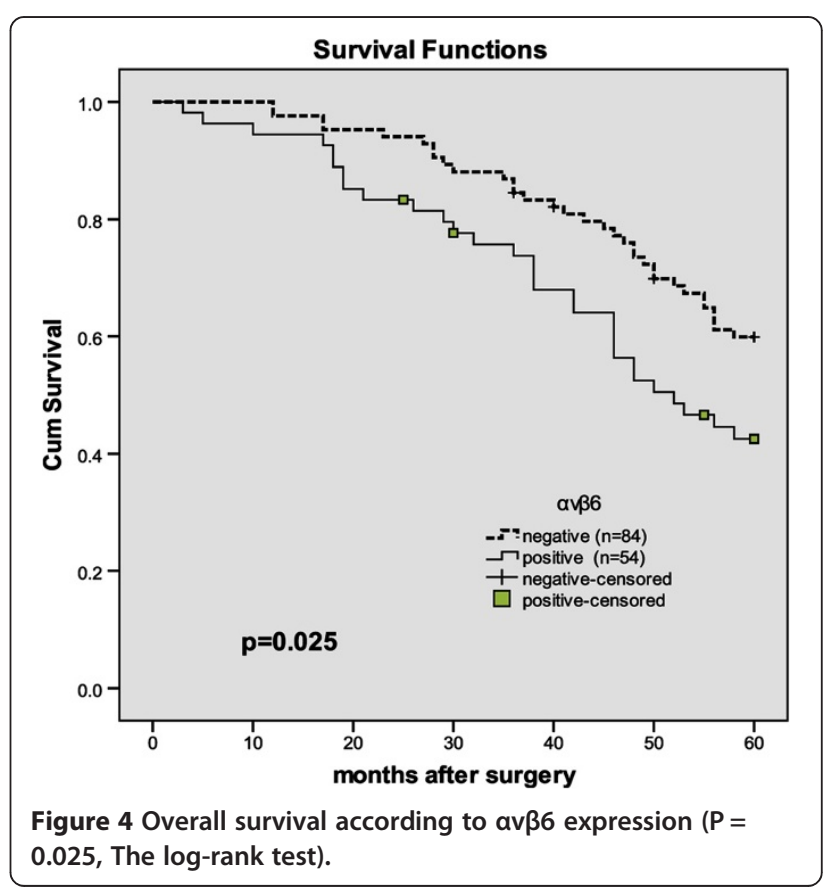


Table 2 Correlation between integrin av $\beta 6$ expression and elF4E expression in human colonic carcinoma tissues ( $r=0.299, P<0.001)$

\begin{tabular}{lccc}
\hline elF4E & \multicolumn{2}{c}{ Integrin $\mathbf{a v \beta 6}$} & Total \\
\cline { 2 - 3 } & Negative & Positive & \\
\hline Low & 49 & 15 & 64 \\
High & 35 & 39 & 74 \\
Total & 84 & 54 & 138 \\
\hline
\end{tabular}

the expression of eIF4E and integrin $\alpha v \beta 6$ are moderatepoorly correlated, and with cautious speculation, they may interact with each other at molecular levels, with significant implications for therapeutic intervention.

\section{Materials and methods Clinical samples}

Our study was a retrospective analysis of patients who had been diagnosed as colon cancer at Qilu Hospital of Shandong University, between January 2006 and July 2008. Included in this study, patients with colon cancer must have received surgical resection as the initial treatment modality without major perioperative complications, had adequate archived tissue kept and complete clinicopathologic data obtained. This resulted in a collection of tissue from 138 patients, 76 males and 62 females with a median age of 57.4 years and an age range of 22-86 years. Based on tumor's anatomical location, we classified colon cancer into right hemicolon cancer (including cecum, ascending colon, and right transverse colon) and left hemicolon cancer (including left transverse colon and descending

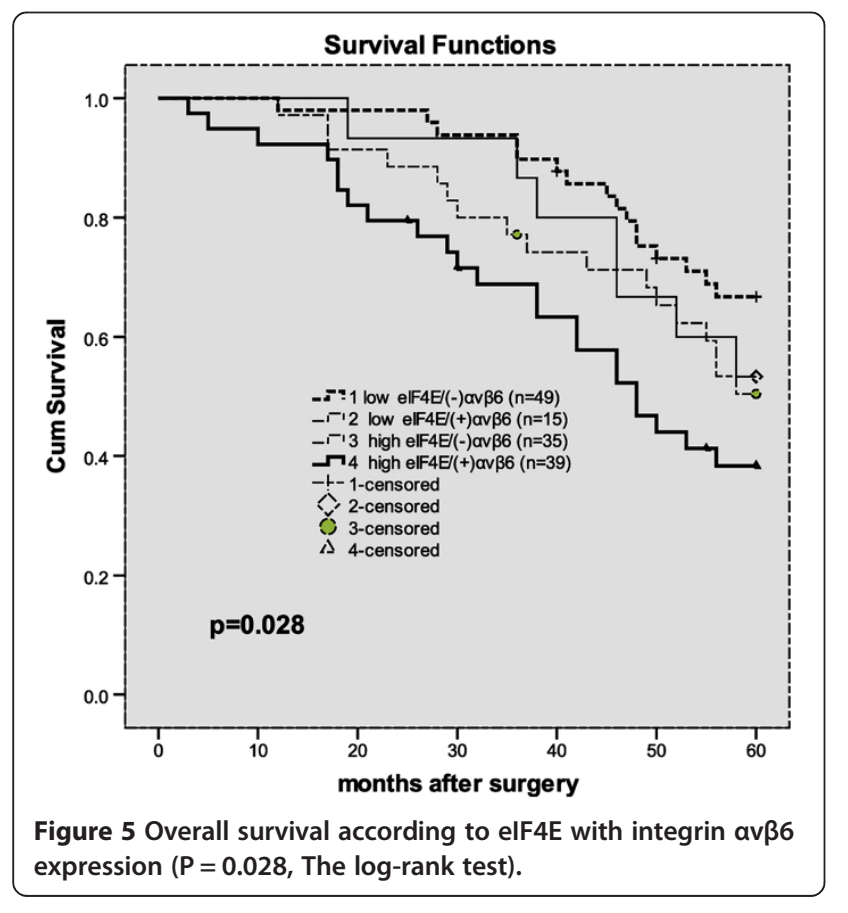

colon). Among those, 63 (45.7\%) were confirmed cancerspecific death within 5 years of prognosis and 75 (54.3\%) were censored as their case follow up was discontinued or patients were alive beyond 60 months or died of reasons other than colon cancer. The pathologic tumor-nodemetastasis (TNM) classification was based on the criteria of the International Union Against Cancer (2009). The study complied with the requirements of The Ethics Committee of Qilu Hospital, Shandong University. And the detailed case characteristics are summarized in Table 1.

\section{Antibodies and TMA-immunohistochemistry}

As primary antibodies, prediluted anti-Integrin $\beta 6$ polyclonal rabbit antibody (1:200; Proteintech Group, Inc., Cat. No.19695-1-AP, Chicago, USA), anti- eIF-4E rabbit monoclonal antibody (1:100; Epitomics, Inc., Cat.No. 1598-1, Burlingame, USA) were used. HRP secondary antibodies and DAB kit were obtained from ZSGB-BIO (Beijing ZSJQB Co., Ltd., Beijing, China).

First, the 138 patients' paraffin blocks were collected from the archive of Pathology Department of Qilu Hospitital. Then colonic tumor tissue microarrays (TMA) were constructed as described previously [28], and two successive $5 \mu \mathrm{m}$-thick TMA sections were cut ready for immunohistochemistry. There were 150 spaced, array pattern cores (1 $\mathrm{mm}$ in diameter) on either section containing 138 carcinoma specimen and 12 paracancerous normal tissue.

Next, immunohistochemical staining for the two markers was done on TMA sections as follows. Sections were incubated for $60 \mathrm{~min}$ at $65^{\circ} \mathrm{C}$, deparafinized and rehydrated using a xylene and ethanol series. Then microwave antigen retrieval was performed: sections were spaced in $250 \mathrm{~mL}$ citrate buffer ( $\mathrm{pH}$ 6.4) for microwaving, with hightemperature for 5 minutes and $40^{\circ} \mathrm{C}$ for 15 minutes. After cooled to room temperature and washed in PBS, the tissue was quenched of endogenous peroxidase by $3 \% \mathrm{H}_{2} \mathrm{O}_{2}$ for 20 minutes, and blocked in goat serum $37^{\circ} \mathrm{C}$ for 40 minutes. Primary antibody incubation was then done by either antibody respectively overnight at $4^{\circ} \mathrm{C}$. The second day, TMA tissue was incubated with universal IgG antibody-Fab-HRP polymer for $30 \mathrm{~min}$; then, DAB and Hematoxylin were stained and terminated in time sequentially. Finally, the samples were observed under light microscope (Olympus Corp, Tokyo, Japan) after sealed with neutral tree gum on slides.

\section{Evaluation of and integrin av $\beta 6$ immunohistochemistry} integrin $\alpha v \beta 6$ was expressed both in cytoplasm and on cellular membrane, mainly seen on the internal surface of the tumor epithelial cell membrane [29]. The expression of eIF4E was mainly observed in cytoplasm of tumor cells. Semi-quantitative expression levels were evaluated by three individuals based on the average intensity and percentage of positively stained tumor cells. Staining intensity was 
Table 3 Univariate and multivariate analysis of association of clinicopathologic features with $\mathbf{5}$-year survival in colon cancer cases

\begin{tabular}{|c|c|c|c|c|c|c|}
\hline \multirow[t]{2}{*}{ Variable } & \multicolumn{3}{|c|}{ Univariate analysis } & \multicolumn{3}{|c|}{ Multivariate analysis } \\
\hline & Relative risk & $95 \% \mathrm{Cl}$ & $\overline{P \text { Value }}$ & Relative risk & $95 \% \mathrm{Cl}$ & $\overline{\text { P Value }}$ \\
\hline Age at diagnosis & 1.091 & $1.063,1.119$ & $<0.001$ & 1.114 & $1.083,1.145$ & $<0.001$ \\
\hline \multicolumn{7}{|l|}{ Gender } \\
\hline Male & 1.000(Ref.) & - & - & & & \\
\hline Female & 0.729 & $0.438,1.212$ & 0.223 & & & \\
\hline \multicolumn{7}{|l|}{ Tumor anatomical location } \\
\hline Right hemicolon cancer & 1.000 (Ref.) & - & - & & & \\
\hline Left hemicolon cancer & 1.000 & $0.610,1.640$ & 0.999 & & & \\
\hline \multicolumn{7}{|l|}{ T stage } \\
\hline $\mathrm{T} 1$ & 0.000 & $0.000,>10^{5}$ & 0.973 & & & \\
\hline $\mathrm{T} 2$ & 0.951 & $0.395,2.290$ & 0.910 & & & \\
\hline $\mathrm{T} 3$ & 1.152 & $0.685,1.937$ & 0.595 & & & \\
\hline T4 & 1.000(Ref.) & - & - & & & \\
\hline \multicolumn{7}{|l|}{ N stage } \\
\hline NO & 1.000 (Ref.) & - & - & & & \\
\hline N1 & 1.308 & $0.760,2.252$ & 0.332 & & & \\
\hline N2 & 1.356 & $0.646,2.843$ & 0.421 & & & \\
\hline \multicolumn{7}{|l|}{ M stage } \\
\hline MO & 1.000 (Ref.) & - & - & & & \\
\hline M1 & 1.308 & $0.697,2.454$ & 0.403 & & & \\
\hline \multicolumn{7}{|l|}{ TNM stage } \\
\hline । & 1.000(Ref.) & - & - & & & \\
\hline$\|$ & 0.634 & $0.242,1.664$ & 0.355 & & & \\
\hline III & 0.998 & $0.378,2.638$ & 0.997 & & & \\
\hline IV & 1.029 & $0.362,2.922$ & 0.957 & & & \\
\hline \multicolumn{7}{|l|}{ Pathology Grade } \\
\hline Well & 1.000(Ref.) & - & - & 1.000(Ref.) & - & - \\
\hline Moderate & 1.666 & $0.912,3.046$ & 0.097 & 1.348 & $0.721,2.519$ & 0.349 \\
\hline Poor/undifferentiated & 1.845 & $0.950,3.583$ & 0.070 & 2.915 & $1.453,5.848$ & 0.003 \\
\hline \multicolumn{7}{|l|}{ elF4E } \\
\hline Low expression & 1.000 (Ref.) & - & - & 1.000 (Ref.) & - & - \\
\hline High expression & 1.885 & $1.128,3.150$ & 0.016 & 2.417 & $1.413,4.134$ & 0.001 \\
\hline \multicolumn{7}{|l|}{$a v \beta 6$} \\
\hline Negative & 1.000 (Ref.) & - & - & 1.000 (Ref.) & - & - \\
\hline Positive & 1.741 & $1.061,2.857$ & 0.028 & 2.393 & $1.421,4.028$ & 0.001 \\
\hline
\end{tabular}

graded as follows: 0 (no staining), 1 (weak staining = light yellow), 2 (moderate staining = yellow brown), and 3 (strong staining $=$ brown). And the percentage of stained tumor cells was scored as 0 (no positive cells), 1 (less than $25 \%$ positive cells), 2 ( $25-50 \%$ positive cells), 3 (more than $50-75 \%$ positive cells), and 4 (more than $75 \%$ positive cells). Consensus results were determined for cores with different initial scores, and ultimate scoring was validated by a consultant histopathologist. An intensity score $\geq 2$ with at least $50 \%$ of tumor cells with positive eIF4E staining was used to classify tumor patients with high expression group,and the others including negative staining were considered as low expression group. In the tumor, positive $\alpha v \beta 6$ staining was judged by the presence of an unequivocal brown staining in the cytoplasm of $10 \%$ or more of tumor cells, the rest were negative. 


\section{Statistical analysis}

Statistical analyses were performed with SPSS 13.0 software. A chi-square test of cross-tabulations and a Fisher exact test were used to examine the relationship between the expression of eIF4E and integrin $\alpha v \beta 6$ and their clinicopathologic characteristics. Survival analyses were conducted by the Kaplan-Meier method and the logrank test. A Spearman correlation was applied to evaluate the relationship between eIF4E and integrin $\alpha v \beta 6$ expression levels. Both univariate and Multivariate analysis for cancer specific deaths were done with the Cox proportional hazard model. P-values $<0.05$ was considered to be statistically significant.

\section{Abbreviations}

elF4E: eukaryotic initiation factor 4E; VEGF: Vascular endothelial growth factor; FGF-2: Fibroblast growth factor; MMP-9: Matrix metalloprotease 9;

ECM: Extracellular matrix; TMA: Tissue microarrays; 4E-BP: 4E-binding protein; PI-3 K: Phosphatidylinositol-3 kinase; mTOR: mammalian target of rapamycin; ERK: Extracellular regulated protein kinase.

\section{Competing interests}

The authors declare that they have no any competing interests.

\section{Authors' contributions}

NJ was responsible for designing of the study and critical review of manuscript; NZ and WJ were responsible for designing and performing of the study, literature research and manuscript writing; MS, SQ, LB were responsible for data acquisition; NW, LE, PC, OS were responsible for data analysis; MS, HZ, LS, ZX were responsible for critical review of manuscript. All authors approved the final version of the manuscript.

\section{Acknowledgements}

We are grateful to Dr. Zhou G. and his colleagues from Department of Pathology, Qilu Hospital for the assistance in the construction and analysis of tissue microarrays. This study was supported by research grant (No. 81272653) from the National Natural Sciences Foundation of China, research grant (No. ZR2013HQ051) from Shandong Province Natural Science Foundation, and research Grant (No. 2012TS133) from the Graduate Independent Innovation Foundation of Shandong University.

\section{Author details}

'Department of Hepatobiliary Surgery, Qilu Hospital, Shandong University, Jinan, Shandong 250012, PR China. ${ }^{2}$ Key Laboratory of Cardiovascular Remodeling and Function Research, Chinese Ministry of Education and Public Health, Jinan, Shandong 250012, PR China.

Received: 27 January 2014 Accepted: 20 March 2014 Published: 28 April 2014

\section{References}

1. Akagi Y, Adachi Y, Kinugasa T, Oka Y, Mizobe T, Shirouzu K: Lymph node evaluation and survival in colorectal cancer: review of population-based, prospective studies. Anticancer Res 2013, 33(7):2839-2847.

2. Carroll M, Borden KL: The oncogene elF4E: using biochemical insights to target cancer. J Interferon Cytokine Res 2013, 33(5):227-238.

3. Berkel HJ, Turbat-Herrera EA, Shi R, de Benedetti A: Expression of the translation initiation factor elF4E in the polyp-cancer sequence in the colon. Cancer Epidemiol Biomarkers Prev 2001, 10(6):663-666.

4. Yang GY, Xu KS, Pan ZQ, Zhang ZY, Mi YT, Wang JS, Chen R, Niu J: Integrin alpha $v$ beta 6 mediates the potential for colon cancer cells to colonize in and metastasize to the liver. Cancer Sci 2008, 99(5):879-887.

5. Joshi B, Cameron A, Jagus R: Characterization of mammalian elF4E-family members. Eur J Biochem 2004, 271:2189-2203.

6. Norton KS, McClusky D, Sen S, Yu H, Meschonat C, Debenedetti A, Li BD: TLK1B Is elevated with elF4E overexpression in breast cancer. J Surg Res 2004, 116:98-103.
7. Nathan CA, Carter P, Liu L, Li BD, Abreo F, Tudor A, Zimmer SG, De Benedetti A: Elevated expression of elF4E and FGF-2 isoforms during vascularization of breast carcinomas. Oncogene 1997, 15:1087-1094.

8. Ruggero D, Montanaro L, Ma L, Xu W, Londei P, Cordon Cardo C, Pandolfi PP: The translation factor elF-4E promotes tumor formation and cooperates with c-Myc in Lymphomagenesis. Nat Med 2004, 10:484-486.

9. De BA, Graff JR: elF-4E expression and its role in malignancies and metastases. Oncogene 2004, 23:3189-3199.

10. Ramos DM, Dang D, Sadler S: The role of the integrin av $\beta 6$ in regulating the epithelial to mesenchymal transition in oral cancer. Anticancer Res 2009, 29:125-130

11. Hood JD, Cheresh DA: Role of integrins in cell invasion and migration. Nat Rev Cancer 2002, 2:91-100.

12. Bates RC, Bellovin DI, Brown C, Maynard E, Wu B, Mercurio AM: Transcriptional activation of integrin $\beta 6$ during the epithelial-mesenchymal transition defines a novel prognostic indicator of aggressive colon carcinoma. J Clin Invest 2005, 115:339-347.

13. Zhang ZY, Xu KS, Wang JS, Yang GY, Wang W, Wang W, Wang JY, Niu WB, Liu EY, Mi YT, Niu J: Integrin av $\beta 6$ acts as a prognostic indicator in gastric carcinoma. Clin Oncol (R Coll Radiol) 2008, 20:61-66.

14. Cantor D, Slapetova I, Kan A, McQuade LR, Baker MS: Overexpression of av $\beta 6$ Integrin Alters the colorectal cancer cell proteome in favor of elevated proliferation and a switching in cellular adhesion that increases invasion. J Proteome Res 2013, 12:2477-2490.

15. Clark EA, Brugge JS: Integrins and signal transduction pathways: The road taken. Science 1995, 268:233-239.

16. Chung J, Kim TH: Integrin-dependent translational control: implication in cancer progression. Microsc Res Tech 2008, 71:380-386.

17. Pópulo H, Lopes JM, Soares P: The mTOR signalling pathway in human cancer. Int J Mol Sci 2012, 13:1886-1918.

18. Ye Q, Cai W, Zheng Y, Evers BM, She QB: ERK and AKT signaling cooperate to translationally regulate survivin expression for metastatic progression of colorectal cancer. Oncogene 2013, 29: doi:10.1038/onc.2013.122.

19. Ferlay J, Shin HR, Bray F, Forman D, Mathers C, Parkin DM: Estimates of worldwide burden of cancer in 2008: GLOBOCAN. Int J Cancer 2008, 2010(127):2893-2917.

20. Wang R, Geng J, Wang JH, Chu XY, Geng HC, Chen LB: Overexpression of eukaryotic initiation factor $4 \mathrm{E}$ (elF4E) and its clinical significance in lung adenocarcinoma. Lung Cancer 2009, 66:237-244.

21. Zimmer SG, DeBenedetti A, Graff JR: Translational control of malignancy: the mRNA cap-binding protein, elF-4E, as a central regulator of tumor formation, growth, invasion and metastasis. Anticancer Res 2000, 20:1343-1351.

22. Graff JR, Zimmer SG: Translational control and metastatic progression: enhanced activity of the mRNA cap-binding protein elF-4E selectively enhances translation of metastasis-related mRNAs. Clin Exp Metastasis 2003, 20:265-273.

23. Ahmed N, Niu J, Dorahy DJ, Gu X, Andrews S, Meldrum CJ, Scott RJ, Baker MS, Macreadie IG, Agrez MV: Direct integrin alphavbeta6 ERK binding implications for tumor growth. Oncogene 2002, 21(9):1370-1380.

24. Zhao-Yang Z, Ke-Sen X, Qing-Si H, Wei-Bo N, Jia-Yong W, Yue-Tang M, Jin-Shen W, Guo-Qiang W, Guang-Yun Y, Jun N: Signaling and regulatory mechanisms of integrin alpha $(\mathrm{v})$ beta6 on the apoptosis of colon cancer cells. Cancer Lett 2008, 266:209-215.

25. Gu X, Niu J, Dorahy DJ, Scott R, Agrez MV: Integrin alpha (v) beta6-associated ERK2 mediates MMP-9 secretion in colon cancer cells. Br J Cancer 2002, 87:348-351.

26. Parsyan A, Hernández G, Meterissian S: Translation initiation in colorectal cancer. Cancer Metastasis Rev 2012, 31:387-395.

27. Hou J, Lam F, Proud C, Wang S: Targeting Mnks for cancer therapy. Oncotarget 2012, 3(2):118-131.

28. Dancau AM, Simon R, Mirlacher M, Sauter G: Tissue microarrays. Methods Mol Biol 2010, 576:49-60.

29. Wang J, Wu J, Hong J, Chen R, Xu K, Niu W, Peng C, Liu E, Wang J, Liu S, Agrez $\mathrm{M}$, Niu J: PKC promotes the migration of colon cancer cells by regulating the internalization and recycling of integrin av $\beta 6$. Cancer Lett 2011, 311:38-47.

doi:10.1186/2045-3701-4-23

Cite this article as: Niu et al:: Protein expression of elF4E and integrin av $\beta 6$ in colon cancer can predict clinical significance, reveal their correlation and imply possible mechanism of interaction. Cell \& Bioscience 2014 4:23. 